Provided for non-commercial research and education use. Not for reproduction, distribution or commercial use.

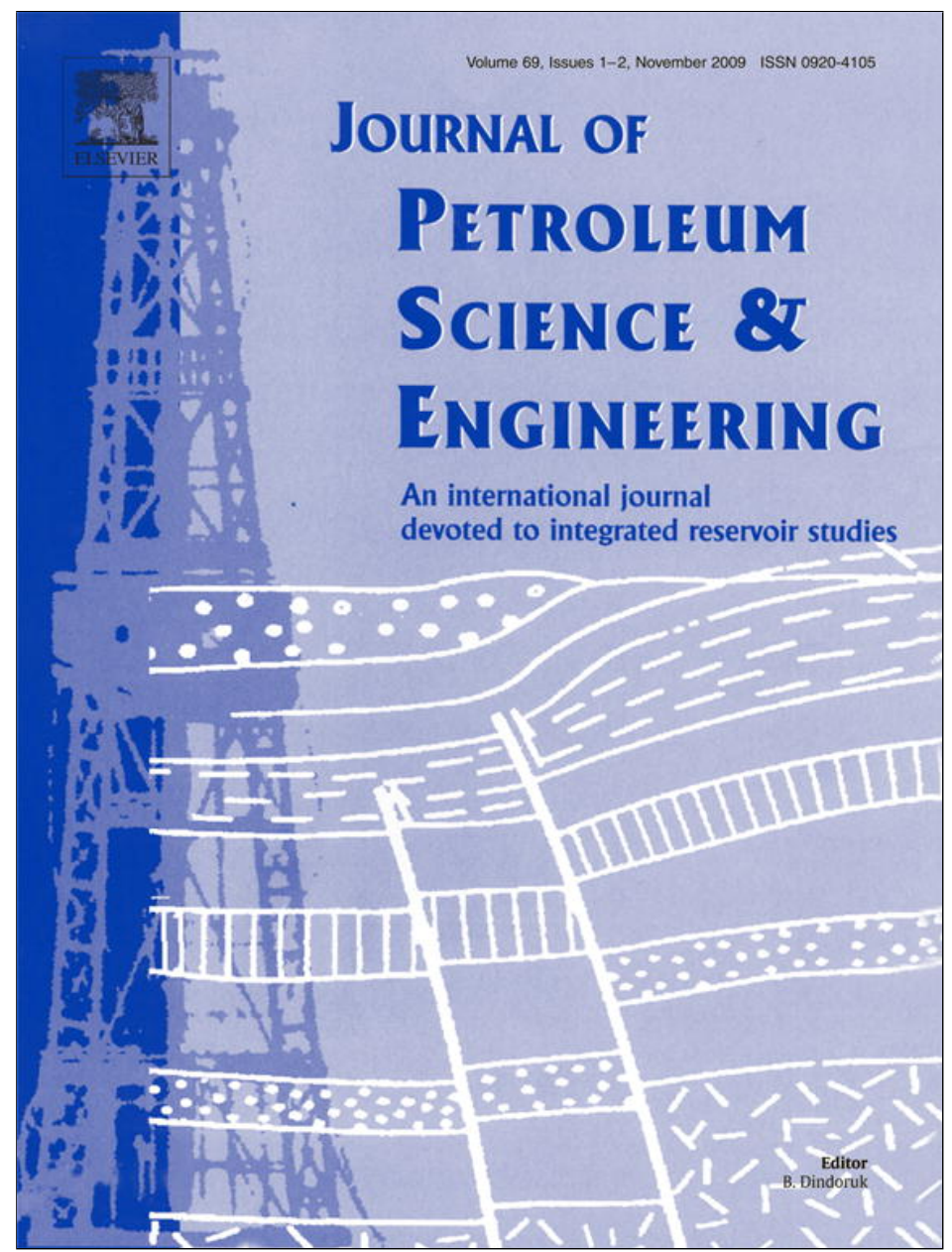

This article appeared in a journal published by Elsevier. The attached copy is furnished to the author for internal non-commercial research and education use, including for instruction at the authors institution and sharing with colleagues.

Other uses, including reproduction and distribution, or selling or licensing copies, or posting to personal, institutional or third party websites are prohibited.

In most cases authors are permitted to post their version of the article (e.g. in Word or Tex form) to their personal website or institutional repository. Authors requiring further information regarding Elsevier's archiving and manuscript policies are encouraged to visit:

http://www.elsevier.com/copyright 
Research paper

\title{
Fracture detection from water saturation log data using a Fourier-wavelet approach
}

\author{
Behzad Tokhmechi a,b,c , Hossein Memarian ${ }^{\text {a,d }}$, Vamegh Rasouli ${ }^{\text {b,*, }}$, \\ Hossein Ahmadi Noubari ${ }^{\text {e,f }}$, Behzad Moshiri ${ }^{\mathrm{e}}$ \\ a School of Mining Engineering, University of Tehran, Tehran, Iran \\ b Department of Petroleum Engineering, Curtin University of Technology, Perth, Australia \\ c Department of Mining Engineering, Geophysics and Petroleum Engineering, Shahrood University of Technology, Shahrood, Iran \\ ' Department of Earth \& Environmental Sciences, University of Waterloo, Ontario, Canada \\ e School of Electrical E' Computer Engineering, Control and Intelligent Processing, Center of Excellence, University of Tehran, Tehran, Iran \\ ${ }^{\mathrm{f}}$ Department of Electrical and Computer Engineering, University of British Colombia, Vancouver, Canada
}

\section{A R T I C L E I N F O}

\section{Article history:}

Received 18 December 2008

Accepted 3 August 2009

\section{Keywords:}

wavelet

wavelet packet

Fourier transform

water saturation

fractured zone

\begin{abstract}
A B S T R A C T
Fracture detection as applied to reservoir characterization is a key step towards modeling of fractured reservoirs. While different methods have been proposed for detection and characterization of fractures and fractured zones, each is associated with certain shortcomings that prevent from their full use in different related engineering application environments. In this paper a new method is proposed for detection of fractured zones and fracture density in which water saturation log data is utilized. For detection of fractures, we have used wavelet transform and properties of wavelets that are highly suitable for detection of changes and local features of data. To choose the optimum mother wavelet, we have used energy matching strategy in which a wavelet with the highest energy match between spectral energy of the signal at the dominant frequency band and the coefficient energy at the same band of wavelet decomposition of the signal is selected. We have used wavelet packet for a more narrow frequency band selection and enhanced results. Decomposing the water saturation data using wavelets showed that the majority of information of the original log is hidden at low frequency bands. As a result, approximated section of wavelet transform of data was used for fracture detection, while shale volume (or gamma ray) log data was used to filter part of the errors in prediction and identification of the uncertain zones. This increased the accuracy of the results by $70 \%$. Finally, a linear relation was derived between energy of approximated section of water saturation log and fracture density, allowing us to estimate the number of fractures in each fractured zone. The method was applied to four wells belonging to one of the Iranian oilfields located in the southwest region of the country and the results are promising. The use of large volume of data and the subsequent analysis increased the generalization ability of the proposed method.
\end{abstract}

(C) 2009 Elsevier B.V. All rights reserved.

\section{Introduction}

Fractures may influence the behaviour of fractured reservoirs such as the fluid flow and production. Therefore in modeling fractured reservoirs understanding fracture properties is important especially in fractured Carbonate reservoirs (Roehl and Choduette, 1985). Fractures can be detected in both direct and indirect manners using seismic sections, petrophysical logs, well tests, well mud loss history

\footnotetext{
* Corresponding author. Department of Petroleum Engineering, Curtin University of Technology, ARRC Building, 26 Dick Perry Avenue, Kensington, Perth, Western Australia, WA 6151, Australia. Tel.: +61 8 92661341; fax: +61 892667063.

E-mail addresses: tokhmechi@ut.ac.ir (B. Tokhmechi), memarian@ut.ac.ir (H. Memarian), v.rasouli@curtin.edu.au (V. Rasouli), noubari@ece.ubc.ca (H.A. Noubari), moshiri@ut.ac.ir (B. Moshiri).
}

and core description (Schlumberger Log Interpretation Principles/ Applications, 1998; Thompson, 2000; Nelson, 2001; Martinez-Torres, 2002; Dutta et al., 2007). However, each of these methods is subjected to some limitations in their use.

Since mid 1980 with the introducing the dipmeter technology as well as image logs the process of fracture detection and characterization of fracture properties such as dip, dip direction, opening, filling etc has become less problematic (Serra, 1989). Having high resolution data acquisition devices, these tools can detect low scale variations. This may lead us to this conclusion that fractures can be fully detected using image logs. However, it is important to note that at the moment there exist other modes to acquire logs data and image data are not the sole source to recover the fractures. This is firstly because it is a recently developed technology which had been made available to the industry around a decade ago and therefore no image log is available 
for wells drilled prior to this period. Secondly, it is a very expensive technology as compared with the costs associated with normal well logging system and hence it is not a common practice to run image logs in every single well drilled.

As modeling the fractures in a reservoir with inadequate volume of data could lead to a misleading interpretation, any direct or indirect technique which may increase our knowledge about the fracture properties is highly valuable. It is important to note that in general fracture modeling is an object based practice which requires larger amount of data comparing to that of pixel based modeling.

Earlier attempts to detect fractures in fractured reservoir include the sonic waves used by Hsu et al. (1987) to study the dip and hydraulic conductivity of fluid through fractures. Flavio and Gregor (1999) used a combined well log called velocity deviation log to study the reservoir properties including fractures. Daiguii et al. (1997) attempted to detect the faults crossing the reservoirs by applying wavelet transform to seismic data. Song et al. (1998) used core data and conventional logs to increase the ability of distinguishing between natural fractures and drilling induced fractures from image logs. Behrens et al. (1998) attempted to detect fractures from seismic data.

Sahimi and Hashemi (2001) applied wavelet transform on porosity log and suggested that high frequency variations correspond to fractures. To validate the model they used permeability log, where a large increase in permeability corresponds to the existence of a fracture. Surjaatmadja et al. (2002) used a frequency decomposition approach to analyse downhole data to detect possible fractures. Martinez-Torres (2002) investigated the use of fuzzy logic of various petrophysical logs for fracture detection. Tran (2004) used classification algorithm to study and detect the fractures.

Dutta et al. (2007) by analysing shear waves identified fault zones. Mohebbi et al. (2007) applied wavelet transform on some logs to detect fractures. Ozkaya and Siyabi (2008) used factor analysis for detecting open fractures near faults and find that mud loss is the best parameter by which such fractures could be detected.

The study of fractures fall into two major categories: a) using number of data resources to detect the fractures; or b) decomposing the data
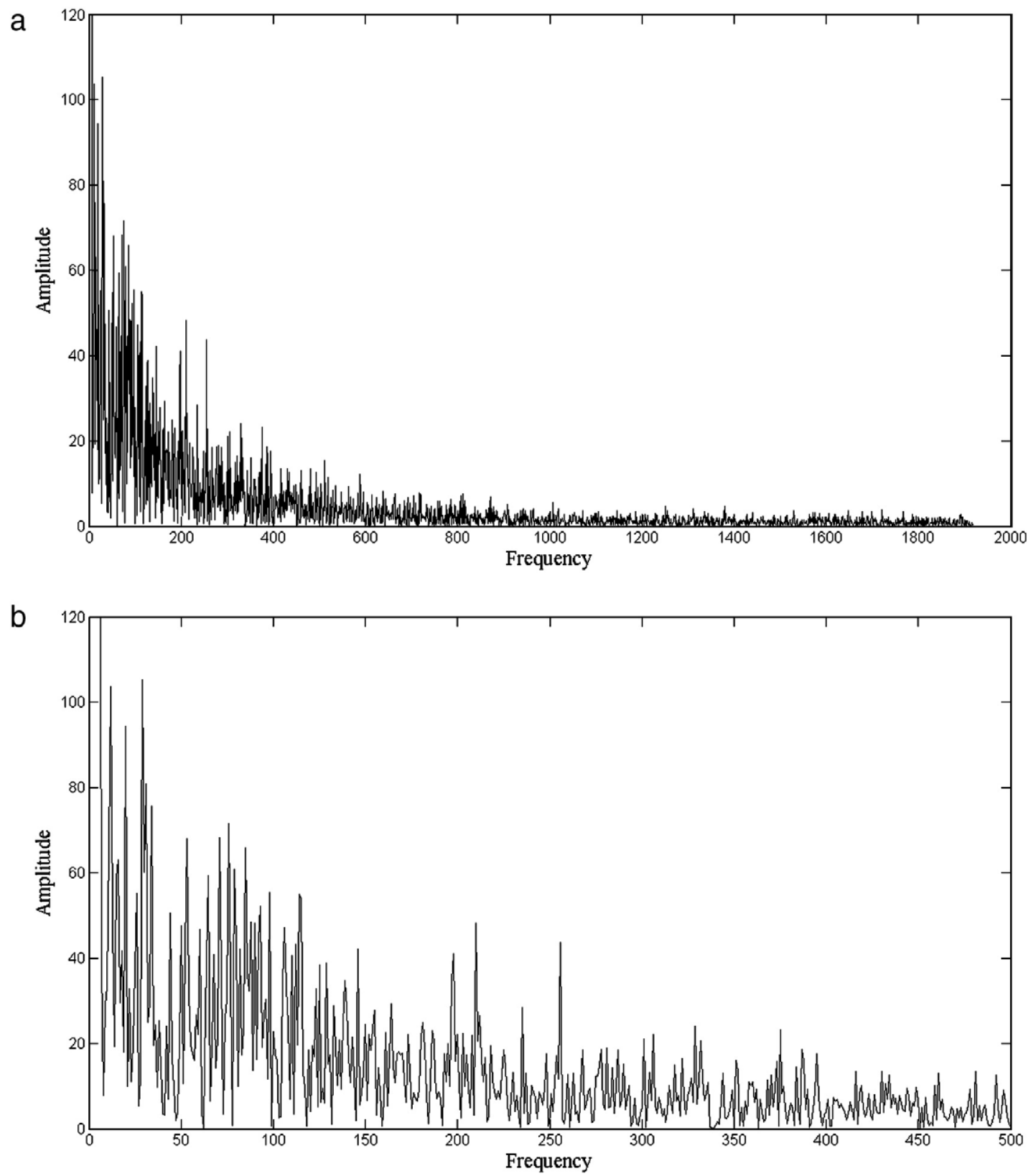

Fig. 1. Fourier transform of water saturation log in one of the studied wells a) over total frequency band and b) at frequencies 0 to $500 \mathrm{~Hz}$. 
Table 1

SSE for water saturation log corresponding to Fourier and mother wavelets in four wells under study.

\begin{tabular}{|c|c|c|c|c|c|c|c|c|}
\hline \multicolumn{2}{|c|}{ Wavelet groups } & \multicolumn{2}{|l|}{$\mathrm{db}$} & \multirow{2}{*}{$\frac{\text { coif }}{\text { coif-5 }}$} & \multirow{2}{*}{$\begin{array}{l}\text { bior } \\
\text { bior-6.8 }\end{array}$} & \multirow{2}{*}{$\begin{array}{l}\text { rbio } \\
\text { rbio-6.8 }\end{array}$} & \multirow{2}{*}{$\frac{\text { sym }}{\text { sym-7 }}$} & \multirow{2}{*}{$\begin{array}{l}\text { Dmey } \\
\text { Dmey }\end{array}$} \\
\hline Well 1 & $\begin{array}{l}\text { Mother } \\
\text { wavelet }\end{array}$ & $d b-1$ & $d b-10$ & & & & & \\
\hline & SSE & 229.25 & 17.82 & 10.16 & 72.54 & 69.89 & 67.09 & 112.27 \\
\hline \multirow[t]{2}{*}{ Well 2} & $\begin{array}{l}\text { Mother } \\
\text { wavelet }\end{array}$ & $d b-1$ & $d b-10$ & coif-2 & bior-4.4 & rbio-1.5 & sym-5 & Dmey \\
\hline & SSE & 67.24 & 17.75 & 17.46 & 15.21 & 15.67 & 22.26 & 27.26 \\
\hline \multirow[t]{2}{*}{ Well 3} & $\begin{array}{l}\text { Mother } \\
\text { wavelet }\end{array}$ & $d b-1$ & $d b-4$ & coif-1 & bior-4.4 & rbio-1.5 & sym-6 & Dmey \\
\hline & SSE & 65.56 & 22.79 & 24.16 & 8.55 & 8.07 & 9.16 & 35.67 \\
\hline \multirow[t]{2}{*}{ Well 4} & $\begin{array}{l}\text { Mother } \\
\text { wavelet }\end{array}$ & $d b-1$ & $d b-3$ & coif-1 & bior-4.4 & rbio-1.3 & sym-4 & Dmey \\
\hline & SSE & 53.43 & 26.78 & 19.53 & 18.67 & 13.16 & 13.67 & 26.2 \\
\hline
\end{tabular}

using mathematical approaches such as wavelet to identify the fractures. The general difficulty attached to both approaches is the lack of adequate volume of data and being unable to identify the accuracy of the method used due to the lack of image logs for calibration purposes. More importantly as the data is inadequate it is impractical to study the possibility of generalization of the results even to nearby wells.

In this paper we use a wavelet technique to decompose the water saturation log to detect fractures. Gamma ray log is used to filter the errors and the results are calibrated against image logs. This has been applied to four wells in one of the oilfields in the southwest of Iran where the sequence of fractured zones with variable fracture density together with intact formation is observed. The results were promising and finally a linear correlation was found between signal energy of water saturation log in fractured zones and the number of fractures. This correlation can be used to determine number of fractures from water saturation log. This work is unique comparing to its similar works in terms of large volume of data used in the analysis which enabled us not only to check the accuracy of the method but also to study the possibility of its generalization.

\section{Wavelet transformer characteristics}

A 1D wavelet has to be used for this study, as the water saturation $\log$ shows the formation characteristics that lie along the formations in vertical direction towards depth. A discrete wavelet transformer
(DWT) of a signal $x(z)$ as defined below (Daubechies, 1988; Mallat, 1989)

$D W T_{x}^{\psi}(\tau, s)=\frac{1}{\sqrt{|s|}} \int x(z) \psi\left(\frac{z-\tau}{s}\right) d z$

transforms signal $x(z)$ using mother wavelet $\psi(z)$ from depth domain $(z)$ to translation $(\tau)$ and scale $(s)$ domain. In Eq. (1), $z-\tau$ is the depth translation. The term $1 / \sqrt{|s|}$ is the normalization factor and removes the scale effect from wavelets with different scales. Note that $s=1 / f$, where $f$ is the frequency (which in this paper corresponds to variability of the studied $\log$ ) and is directly proportional to the width of the window function, which is to say that mother wavelet carries the characteristics of window function. An increase in scale $s$ (i.e. smaller frequency) corresponds to a larger window being analysed, which reduces the ability in depth resolution but increases the frequency resolution ability. Therefore by increasing the scale, smaller frequency bands are detected and resolution efficiency in frequency domain increases whereas this ability reduces in depth domain.

In this research signal energy matching algorithm is used to choose the optimum mother wavelet in order to analyse the water saturation $\log$, where the signal is firstly transformed from depth-wavelength domain to frequency-wavelength using a Fourier transformer to detect the dominant frequencies. Then the signal is analysed using different mother wavelets. To choose the optimum mother wavelet, we have used energy matching strategy in which a wavelet with the highest energy match between spectral energy of the signal at the dominant frequency band and the coefficient energy at the same band is selected. We have used wavelet packet for a more narrow frequency band selection and enhanced results (Burrus et al., 1997).

In Fig. 1(a) the water saturation log corresponding to one of the studied wells is shown. As is seen from this figure the majority of signal energy resides at low frequencies. As a result and based on signal energy matching strategy the proper mother wavelet should be sought for using wavelet transform coefficients at low frequencies.

Although it is believed that the wavelet transform leads to satisfactory results, in order to increase the certainty in choosing the proper mother wavelet, wavelet packet transform is used in this study. This is advantageous as the wavelet packet transform is flexible in choosing the frequency bands which are in better agreement with signal energy. Also, to increase the accuracy in calculating signal energy the
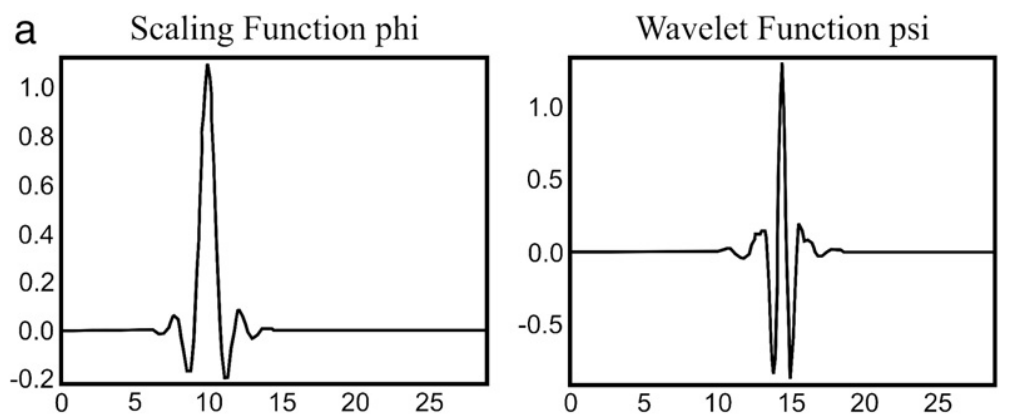

\section{b}
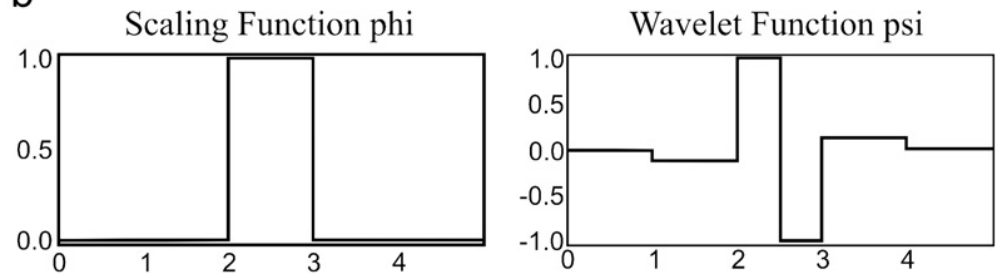

Fig. 2. Wavelet and scaling functions of optimum mother wavelets used to analyse water saturation logs in a) well 1 (coif-5) and b) well 4 (rbio-1.3). 
Table 2

Signal energy percentage of water saturation log at low frequencies in four wells under study.

\begin{tabular}{|c|c|c|c|c|c|c|c|c|c|c|}
\hline \multicolumn{2}{|c|}{ Well 1 Frequency } & $1-30$ & $\begin{array}{l}31- \\
60\end{array}$ & $\begin{array}{l}61- \\
90\end{array}$ & $\begin{array}{l}91- \\
120\end{array}$ & $\begin{array}{l}121- \\
150\end{array}$ & $\begin{array}{l}151- \\
180\end{array}$ & $\begin{array}{l}181- \\
210\end{array}$ & $\begin{array}{l}211- \\
240\end{array}$ & $\begin{array}{l}1- \\
240\end{array}$ \\
\hline & $\begin{array}{l}\text { Signal } \\
\text { energy (\%) }\end{array}$ & 93.44 & 1.34 & 1.67 & 1.06 & 0.54 & 0.29 & 0.44 & 0.19 & 98.98 \\
\hline \multirow[t]{2}{*}{$\begin{array}{c}\text { Well } \\
2\end{array}$} & $\begin{array}{l}\text { Frequency } \\
\text { range }(\mathrm{Hz})\end{array}$ & $1-24$ & $\begin{array}{l}25- \\
48\end{array}$ & $\begin{array}{l}49- \\
72\end{array}$ & $\begin{array}{l}73- \\
96\end{array}$ & $\begin{array}{l}97- \\
120\end{array}$ & $\begin{array}{l}121- \\
144\end{array}$ & $\begin{array}{l}145- \\
165\end{array}$ & $\begin{array}{l}166- \\
187\end{array}$ & $\begin{array}{l}1- \\
187\end{array}$ \\
\hline & $\begin{array}{l}\text { Signal } \\
\text { energy (\%) }\end{array}$ & 98.47 & 0.46 & 0.22 & 0.24 & 0.16 & 0.12 & 0.05 & 0.07 & 99.78 \\
\hline \multirow[t]{2}{*}{$\begin{array}{c}\text { Well } \\
3\end{array}$} & $\begin{array}{l}\text { Frequency } \\
\text { range }(\mathrm{Hz})\end{array}$ & $1-14$ & $\begin{array}{l}15- \\
28\end{array}$ & $\begin{array}{l}29- \\
42\end{array}$ & $\begin{array}{l}43- \\
56\end{array}$ & $\begin{array}{l}57- \\
70\end{array}$ & $\begin{array}{l}71- \\
82\end{array}$ & $\begin{array}{l}83- \\
96\end{array}$ & $\begin{array}{l}97- \\
110\end{array}$ & $\begin{array}{l}1- \\
110\end{array}$ \\
\hline & $\begin{array}{l}\text { Signal } \\
\text { energy (\%) }\end{array}$ & 96.95 & 1.01 & 0.27 & 0.29 & 0.31 & 0.12 & 0.15 & 0.24 & 99.32 \\
\hline \multirow[t]{2}{*}{$\begin{array}{c}\text { Well } \\
4\end{array}$} & $\begin{array}{l}\text { Frequency } \\
\text { range }(\mathrm{Hz})\end{array}$ & $1-19$ & $\begin{array}{l}20- \\
37\end{array}$ & $\begin{array}{l}38- \\
56\end{array}$ & $\begin{array}{l}57- \\
74\end{array}$ & $\begin{array}{l}75- \\
93\end{array}$ & $\begin{array}{l}94- \\
111\end{array}$ & $\begin{array}{l}112- \\
129\end{array}$ & $\begin{array}{l}130- \\
147\end{array}$ & $\begin{array}{l}1- \\
147\end{array}$ \\
\hline & $\begin{array}{l}\text { Signal } \\
\text { energy (\%) }\end{array}$ & 95.84 & 1.22 & 0.56 & 0.35 & 0.35 & 0.40 & 0.16 & 0.18 & 99.07 \\
\hline
\end{tabular}

white noise has been reduced. In Fig. 1(b) the corresponding Fourier transform is shown in the frequency range of 0 to $500 \mathrm{~Hz}$.

To choose the optimum mother wavelet, the Fourier transform of water saturation $\log$ in all 4 wells was acquired and the dominant frequencies were analysed. As it is seen from Fig. 1 majority of signal energy is hidden in low frequency bands. To arrive at a more focused energy matching results, it was decided to decompose signals up to seven levels using wavelet packet and in this way optimum frequency bands corresponding to more accurate signal energy were chosen. As an example, in Fig. 1 eight frequency bands of 1-30, 31-60 and up to 211240 were selected. The energy of the hidden signals in these eight bands was calculated using Fourier and wavelet packet transforms and defining the difference between them as a measure of error, the sum of square error (SSE) as shown in the Table 1 was obtained. For instance, in Table 1 SSE is given for four of these wells. From this table it is seen that different mother wavelets are available to be used for decomposition of water saturation in four wells in one field, however for each well different mother wavelets from any mother wavelets family found to be optimum. For comparison, the performance of mother wavelet $d b 1$ in four wells are given, which indicates that the performance of this mother wavelet in all wells is weaker as compared with that of optimum mother wavelets using different wavelets. It is also seen that to analyse the water saturation log in each well the optimum mother wavelet should be nominated. For wells 1 to 4 shown in Table 1 the chosen optimum mother wavelets are coif-5, rbio-1.3, bior-4.4 and rbio-1.5, respectively. In Fig. 2(a) and (b) wavelet and scaling functions corresponding to coif-5 and rbio-1.3 are shown.

\section{Water saturation response to fractures}

Water saturation is defined as the ratio of water to formation fluid. Archie equation as the most commonly used method to calculate water saturation is used here which is written as (Schlumberger Log Interpretation Principles/Applications, 1998):

$S_{\mathrm{w}}^{n}=\frac{F R_{\mathrm{w}}}{R_{\mathrm{t}}}$

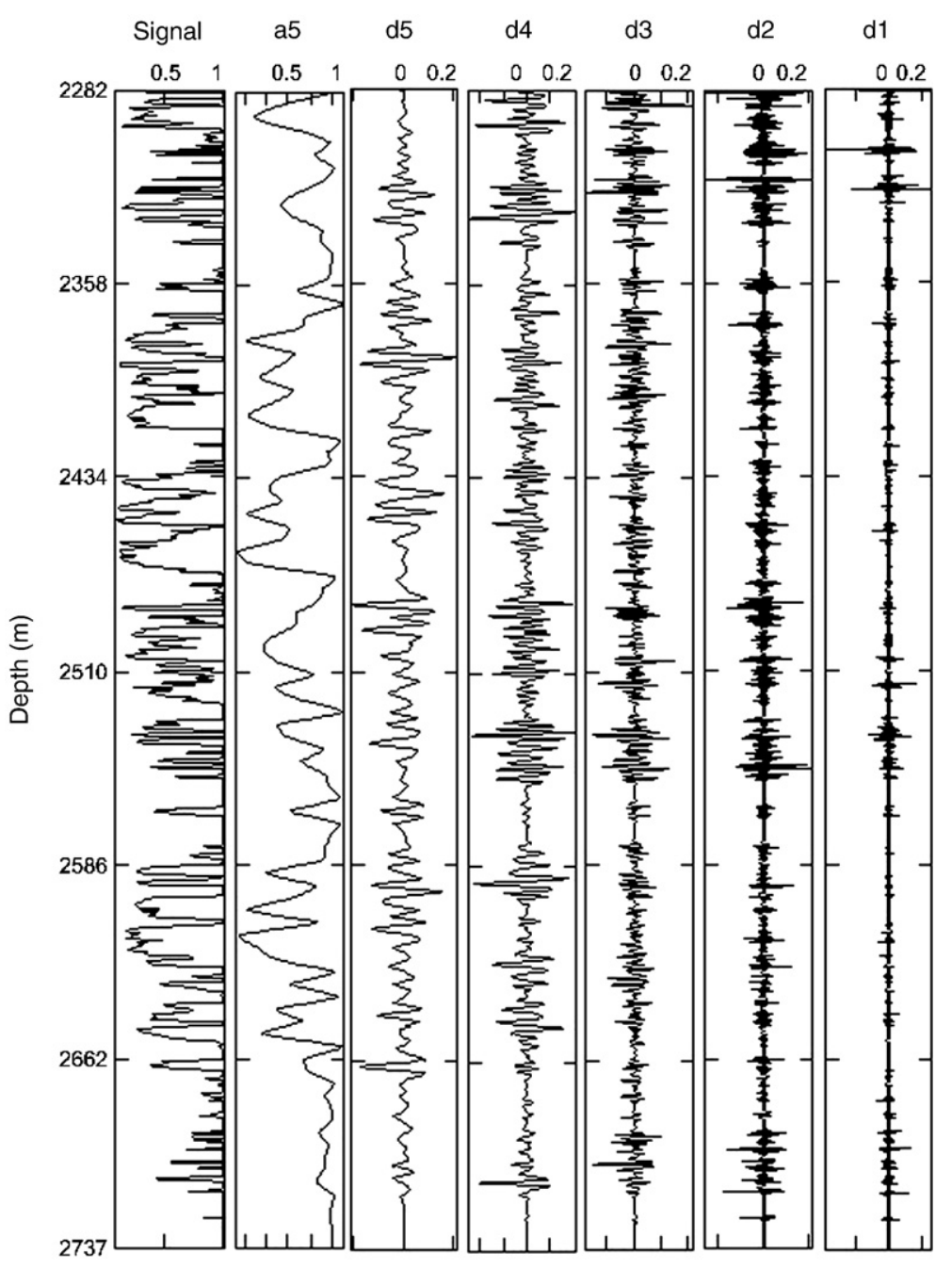

Fig. 3. Decomposing water saturation log in well 2 using mother wavelet bior-4.4. 


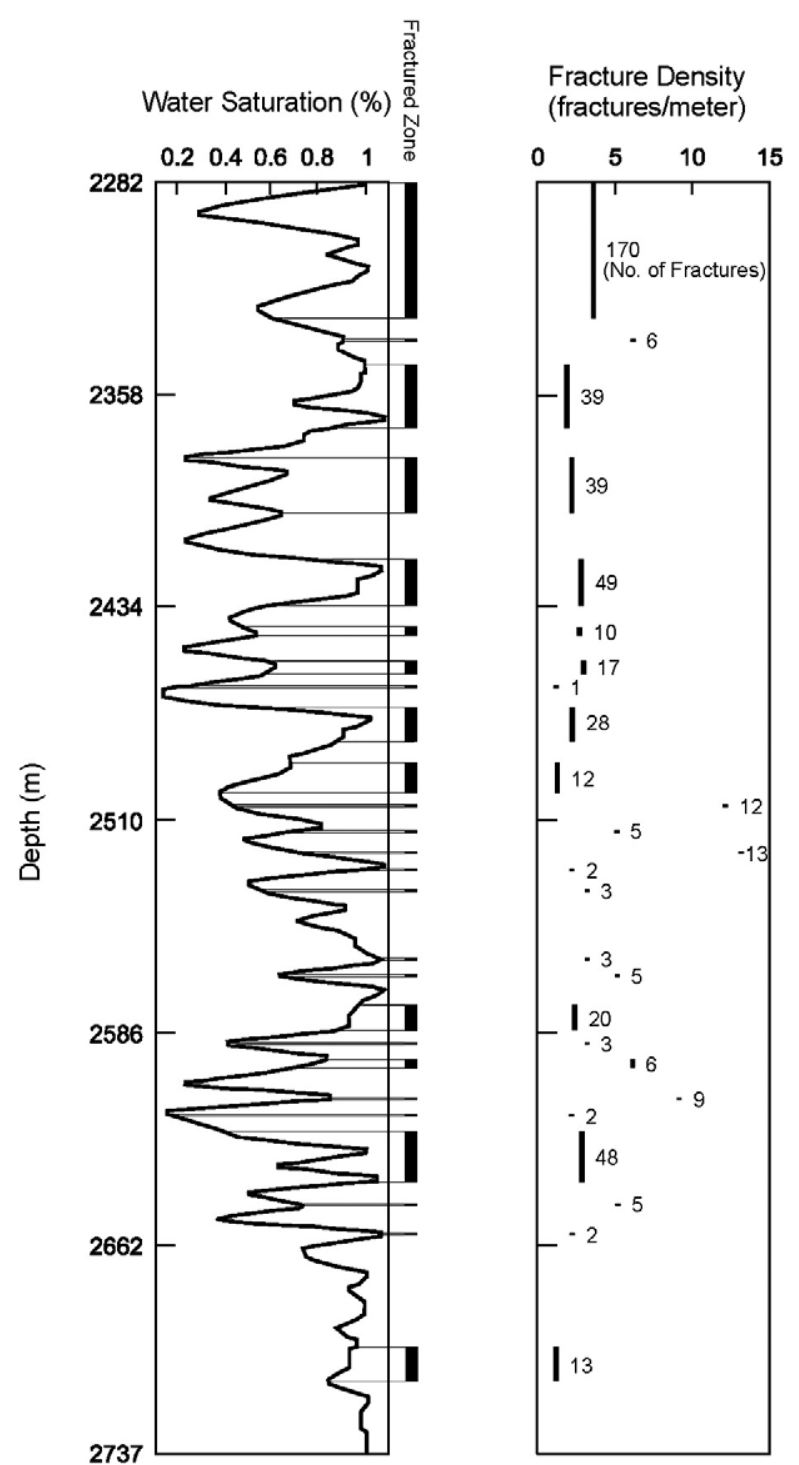

Fig. 4. Location of fractured zones on approximated section of signal in Fig. 3.

where $S_{\mathrm{w}}$ is water saturation, $F$ is the formation coefficient, $R_{\mathrm{w}}$ and $R_{\mathrm{t}}$ are electrical resistivity of formation water and formation rock, respectively. Power factor $n=2$ used in this research. $R_{\mathrm{o}}=F R_{\mathrm{w}}$ is the electrical resistivity of a formation which is $100 \%$ saturated with water with electrical resistivity of $R_{\mathrm{w}}$.
Table 4

Fracture recovery results in well 2.

\begin{tabular}{lcc}
\hline Type of error & Corresponding depth & Recovery \\
\cline { 2 - 2 } & $(\mathrm{m})$ & $(\%)$ \\
\hline No error & 290 & 64 \\
FP & 54 & 12 \\
FN & 44 & 9 \\
Uncertain & 67 & 15 \\
\hline
\end{tabular}

Water saturation log is sensitive to fractures where a certain effect is observed under fracture condition. Three reasons to support this statement are given below:

a) In water wet reservoir rocks as the contact area between fluid and rock increases, the amount of water increases accordingly, which means that at fracture location the water saturation levels is expected to be higher. The percentage of this increase depends on fracture opening (aperture) so that an increase in fracture opening (aperture) across hydrocarbon bearing section of the reservoir causes a relatively lower increase in water saturation. Clearly, the closed fractures do not show any response to water saturation. Therefore it appears that water saturation could be potentially used as a means to separate open and closed fractures. This study is carried out using data from a water wet reservoir formation.

b) If a water based mud is used in drilling, a part of water exists in mud will penetrate through the open fractures and replaces hydrocarbon, which results in an increase in water saturation (Fathi et al., 2008). In order for maximum replacement to be taken place about two days of time interval is required as concluded by Fathi et al. (2008). As, in general, well logging is performed after more than two days upon completion of drilling a section of a well, it is not unrealistic to expect an increase in water saturation level in open fractures. Again, this shows that water saturation is potentially a useful parameter to distinguish between open and closed fractures. In the reservoir under study here a water based mud was used during drilling.

c) Water coning causes water saturation to become higher in upper reservoir section. The reservoir studied here is producing for many years now and the wells under study in this work have been drilled recently. The reservoir is a fractured Carbonate reservoir and as expected the fluid flow is mainly across fractures (Nelson, 2001) which means larger water saturation in fractured zones.

\section{Wavelet transform applied to water saturation $\log$}

Fourier transform was applied to water saturation logs belonging to 4 wells as shown in Table 1 . Different frequency bands are considered to calculate the signal energy. The results are summarized

Table 3

Comparing water saturation against reservoir fractures in well 2.

\begin{tabular}{|c|c|c|c|c|c|c|c|c|c|c|c|}
\hline \multirow[t]{2}{*}{ Row } & \multirow{2}{*}{$\frac{\text { Depth }}{(\mathrm{m})}$} & \multirow{2}{*}{$\frac{\text { Thickness }}{(\mathrm{m})}$} & \multirow[t]{2}{*}{ Result $^{\mathrm{a}}$} & \multirow[t]{2}{*}{ Row } & \multirow{2}{*}{$\frac{\text { Depth }}{(\mathrm{m})}$} & \multirow{2}{*}{$\frac{\text { Thickness }}{(\mathrm{m})}$} & \multirow[t]{2}{*}{ Result $^{\mathrm{a}}$} & \multirow[t]{2}{*}{ Row } & \multirow{2}{*}{$\frac{\text { Depth }}{(\mathrm{m})}$} & \multirow[t]{2}{*}{ Thickness } & \multirow[t]{2}{*}{ Result } \\
\hline & & & & & & & & & & & \\
\hline 1 & $2282-2286$ & 5 & + & 11 & $2501-2507$ & 7 & + & 21 & $2579-2606$ & 28 & + \\
\hline 2 & $2287-2296$ & 10 & FN & 12 & $2508-2513$ & 6 & FP & 22 & $2607-2609$ & 3 & FP \\
\hline 3 & $2297-2322$ & 26 & + & 13 & $2514-2521$ & 8 & + & 23 & $2610-2630$ & 21 & + \\
\hline 4 & $2323-2330$ & 8 & FN & 14 & $2522-2529$ & 8 & FP & 24 & $2631-2636$ & 6 & FN \\
\hline 5 & $2331-2357$ & 27 & + & 15 & $2530-2536$ & 7 & + & 25 & $2637-2655$ & 19 & + \\
\hline 6 & $2358-2362$ & 5 & FN & 16 & $2537-2542$ & 6 & FP & 26 & $2656-2660$ & 5 & FP \\
\hline 7 & $2363-2389$ & 27 & + & 17 & $2543-2546$ & 4 & + & 27 & $2661-2669$ & 9 & + \\
\hline 8 & $2390-2397$ & 8 & FN & 18 & $2547-2561$ & 15 & FP & 28 & $2670-2737$ & 67 & UN \\
\hline 9 & $2398-2493$ & 96 & + & 19 & $2562-2567$ & 6 & + & & & & \\
\hline 10 & $2494-2500$ & 7 & FN & 20 & $2568-2578$ & 11 & $\mathrm{FP}$ & & & & \\
\hline
\end{tabular}

a $(+)$ correct answer, (FP) false positive error, (FN) false negative error, (UZ) uncertain zone. 


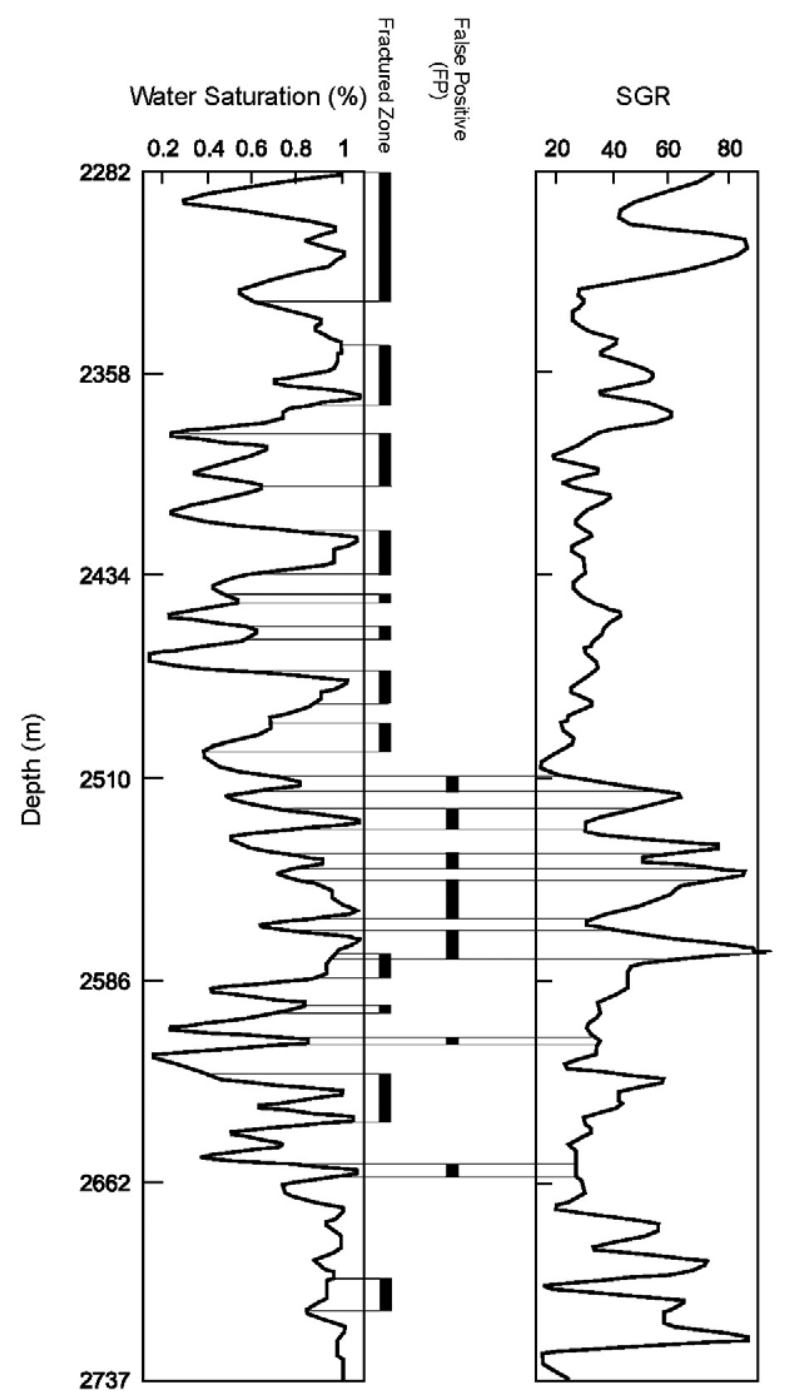

Fig. 5. Approximated $S_{\mathrm{w}}$ and GR logs in well 2 analysed using mother wavelet bior-4.4 at level 5. Fractured zones and FP errors are shown.

in Table 2. From this table and also Fig. 1 it is seen that most of the signal energy of water saturation log is hidden at low frequencies.

As in general the signal frequency varies between 0 and $2000 \mathrm{~Hz}$ in all wells (see Fig. 1(a) for example), Table 2 leads to the conclusion that more than $99 \%$ of the information is hidden in low frequency bands (as seen in the most right column in Table 2). As an example, in well 3, more than $99.3 \%$ of signal energy is hidden within frequencies of $1-110 \mathrm{~Hz}$ (i.e. within about $5 \%$ of total frequency range).

Also in this well about 97\% of signal energy is concentrated near zero frequency. Thus, it is not advisable to search for the information from water saturation log at high frequency, it is also certainly very difficult to generalize these results to other wells and careful attention is required. As

Table 5

Non-fractured zones depth intervals in well 2 after applying GR filtering.

\begin{tabular}{|c|c|c|c|c|c|}
\hline \multirow[t]{2}{*}{ No. } & Depth interval & Thickness & No. & Depth interval & Thickness \\
\hline & $(\mathrm{m})$ & (m) & & $(\mathrm{m})$ & $(\mathrm{m})$ \\
\hline 1 & $2282-2288$ & 7 & 6 & $2542-2552$ & $11^{\mathrm{a}}$ \\
\hline 2 & 2304-2319 & 16 & 7 & $2571-2578$ & $8^{a}$ \\
\hline 3 & $2372-2374$ & $3^{\mathrm{a}}$ & 8 & $2689-2696$ & $8^{a}$ \\
\hline 4 & $2516-2518$ & $3^{\mathrm{a}}$ & 9 & $2706-2709$ & 4 \\
\hline 5 & $2534-2538$ & $5^{a}$ & 10 & $2717-2723$ & $7^{\mathrm{a}}$ \\
\hline
\end{tabular}

${ }^{\mathrm{a}}$ Intervals where filtering detected fractures correctly.

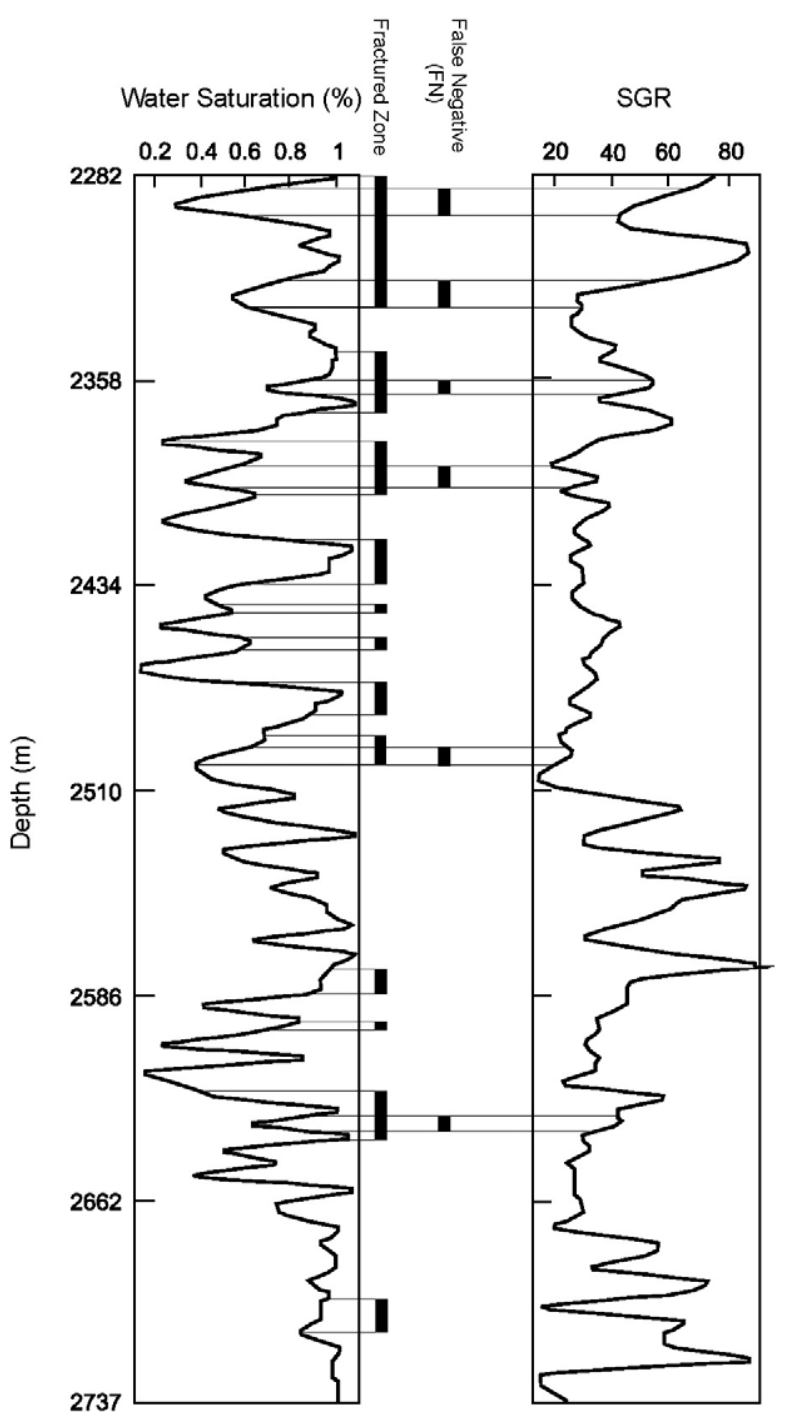

Fig. 6. Approximated $S_{\mathrm{w}}$ and GR logs in well 2 analysed using mother wavelet bior-4.4 at level 5. Fractured zones and FN errors are shown.

a result, in this research low frequency signals are used to study and develop the correlation between fractures and water saturation. For this reason wavelet approximation is utilized. In Fig. 3 water saturation log corresponding to well 2 and its decomposed frequencies up to five levels using mother wavelet bior-4.4 (the optimum mother wavelet for signal processing in this well as seen in Table 1 ) is shown. As seen, in this figure it is a reduction in signal frequency as we move from bottom to top. Therefore $d 1$ and $a 5$ represent the maximum and minimum signal frequencies (variations), respectively. As the majority of signal

Table 6

Filtering uncertain zones to improve detecting fractured zones.

\begin{tabular}{lllll}
\hline Zone category & $\begin{array}{l}\text { Detecting } \\
\text { fractured } \\
\text { zone }\end{array}$ & $\begin{array}{l}\text { Shale } \\
\text { volume or } \\
\text { GR log } \\
\text { variation }\end{array}$ & $\begin{array}{l}\text { Reservoir } \\
\text { zone }\end{array}$ & $\begin{array}{l}\text { Definition } \\
\text { of } \\
\text { uncertain } \\
\text { zone }\end{array}$ \\
\hline Uncertain & Impossible & Any & $\begin{array}{l}\text { Water } \\
\text { bearing }\end{array}$ & $\begin{array}{l}\text { No } \\
\text { variation } \\
\text { Non-fractured }\end{array}$ \\
$\begin{array}{llll}\text { Reduced shale volume or } \\
\text { GR coincide with fractured } \\
\text { zone and remaining } \\
\text { zones are non-fractured }\end{array}$ & Possible & $\begin{array}{l}\text { No } \\
\text { variation }\end{array}$ & $\begin{array}{l}\text { Hydrocarbon } \\
\text { bearing }\end{array}$ & $\begin{array}{l}\text { saturation } \\
\text { log }\end{array}$ \\
\hline
\end{tabular}




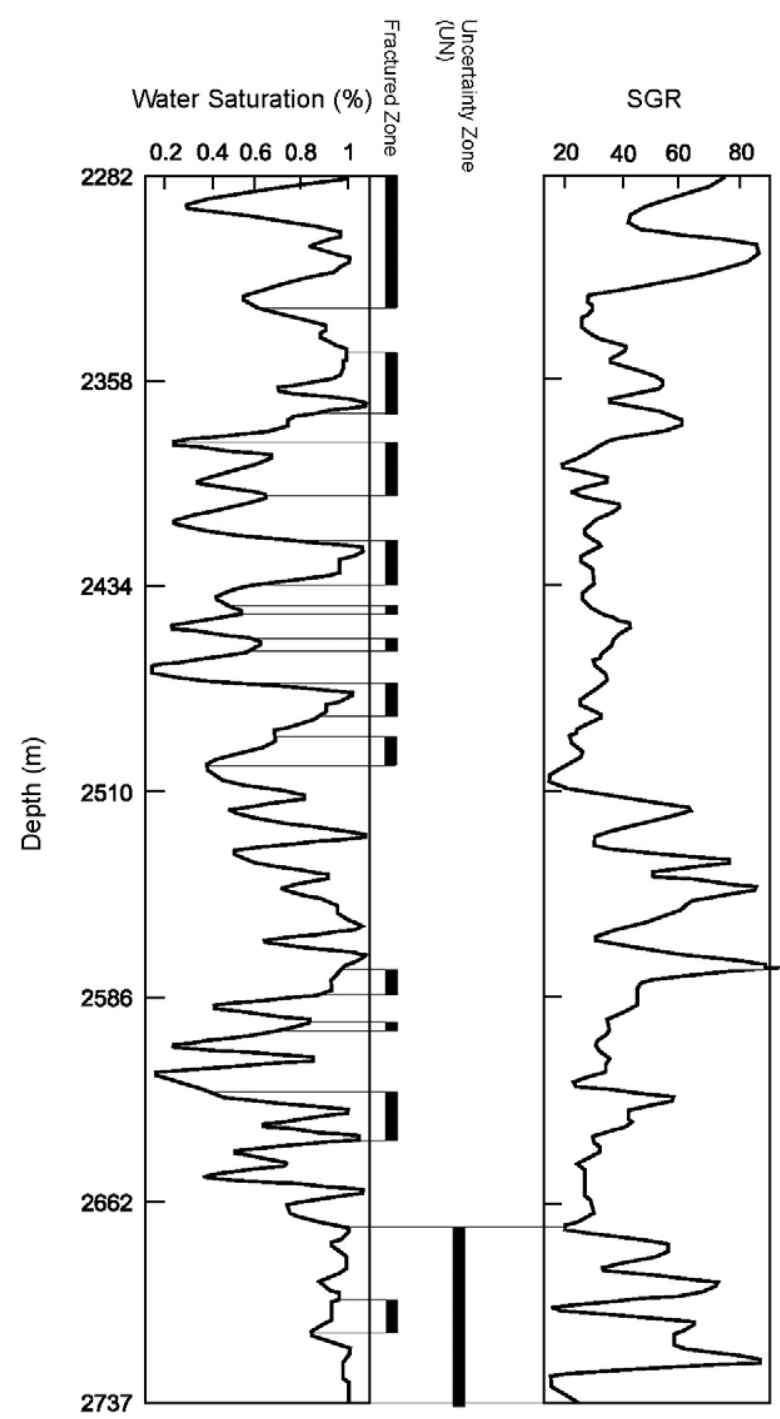

Fig. 7. Approximated $S_{\mathrm{w}}$ and GR logs in well 2 analysed using mother wavelet bior-4.4 at level 5. Fractured zones and uncertain zones are shown.

information is hidden at low frequency bands, the fractured zones are searched at low frequencies (a5). The reservoir section is between $2282 \mathrm{~m}$ and $2737 \mathrm{~m}$, i.e. the studied depth has a thickness of $455 \mathrm{~m}$.

In Fig. 4 location of fractured zones has been mapped into signal approximated section of water saturation log in well 2 (see Fig. 3). In this figure also fracture density and number of fractures in each zone are shown. From this figure, a reduction in water saturation is observed from depth $2282 \mathrm{~m}$ to $2297 \mathrm{~m}$; this is while the image log for this well indicates this zone to be a fractured zone. The depth interval of $2297 \mathrm{~m}$ to $2320 \mathrm{~m}$ corresponds to a fractured zone with an increase in water saturation value. Again, across the next $10 \mathrm{~m}$ of the reservoir where the formation is fractured, a reduction in water saturation is seen. This concludes that although, in general, the fractured zones correspond to increased water saturation there are situations where this criterion cannot be validated; i.e. increase in water saturation in non-fractured zones or reduction of water saturation in fractured zones. In Table 3 a summary of this trend is shown on water saturation $\log$ in well 2. As discussed earlier two types of errors may happen; if water saturation increases (positive response from log) but no fractured zone exist (false interpretation), this is shown as false positive (FP) error. Similarly false negative (FN) error stands for the situation where water saturation reduces (negative response from $\log$ ) but fractured zone is observed (false interpretation).

It is important to mention that in this work single fractures, as seen in Fig. 4, are not considered as fractured zones and therefore this explains the disagreement between Fig. 4 and Table 3 at some depths.

Here, instead of having one single threshold for water saturation along the total well depth, the variation in water saturation is compared with some local threshold levels where each is set at different depth interval and where water saturation values are relatively similar.

From Table 3 it is found that using water saturation log the total of $290 \mathrm{~m}$ of fractured zones were detected across the total $455 \mathrm{~m}$ of reservoir section, i.e. a recovery of $64 \%$. The FP and FN errors account for $12 \%$ (total depth of $54 \mathrm{~m}$ ) and $9 \%$ (total depth of $44 \mathrm{~m}$ ), respectively. The method appears to be inefficient across the remaining depth of $67 \mathrm{~m}$ (corresponding to 15\% of the total depth), which is at the lower depth of reservoir, as water saturation does not show much variability in this zone. Table 4 summarizes the results.

Similar results were obtained for other wells in terms of recovery performance for the fractured zones, which perhaps is indicative of the applicability of the approach for the purpose of fracture detection.

\section{Filtering the errors}

To reduce the errors encountered in fracture detection approach discussed in the previous section, other petrophysical logs are proposed to be used as additional information sources to filter different types of errors.

\subsection{False positive (FP) error}

This error occurs when water saturation increases across a section but no fracture exists in reality, which is against the fundamental concept adopted before. In this situation, an increase in water saturation is due to other reasons which need to be investigated in order to filter the FP type error.

In water wet reservoir formations a reduction in porosity or an increase in capillary pressure could potentially lead to increasing water saturation. Both of these could potentially happen in shale formations simultaneously. Therefore the shale volume or gamma ray (particularly Potassium) log appears to be an appropriate filter for FP

Table 7

Fracture recovery results in well 2 after filtering FP errors.

\begin{tabular}{|c|c|c|c|c|c|c|c|c|c|c|c|}
\hline \multirow[t]{2}{*}{ Row } & Depth & \multirow[t]{2}{*}{ Thickness } & \multirow[t]{2}{*}{ Result $^{\mathrm{a}}$} & \multirow[t]{2}{*}{ Row } & \multirow{2}{*}{$\frac{\text { Depth }}{(\mathrm{m})}$} & \multirow{2}{*}{$\frac{\text { Thickness }}{(\mathrm{m})}$} & \multirow[t]{2}{*}{ Result $^{\mathrm{a}}$} & \multirow[t]{2}{*}{ Row } & \multirow{2}{*}{$\frac{\text { Depth }}{(\mathrm{m})}$} & \multirow{2}{*}{$\frac{\text { Thickness }}{(\mathrm{m})}$} & \multirow[t]{2}{*}{ Result } \\
\hline & $(\mathrm{m})$ & & & & & & & & & & \\
\hline 1 & $2282-2288$ & 7 & $\mathrm{FE}$ & 8 & $2358-2362$ & 5 & FN & 15 & $2610-2630$ & 21 & + \\
\hline 2 & 2289-2296 & 8 & FN & 9 & $2363-2389$ & 27 & + & 16 & $2631-2636$ & 6 & FN \\
\hline 3 & 2297-2303 & 7 & + & 10 & $2390-2397$ & 8 & FN & 17 & $2637-2655$ & 19 & + \\
\hline 4 & 2304-2319 & 16 & FE & 11 & 2398-2493 & 96 & + & 18 & $2656-2660$ & 5 & FP \\
\hline 5 & $2320-2322$ & 3 & + & 12 & $2494-2500$ & 7 & FN & 19 & $2661-2669$ & 9 & + \\
\hline 6 & $2323-2330$ & 8 & FN & 13 & 2501-2606 & 106 & + & 20 & $2670-2737$ & 67 & UN \\
\hline 7 & $2331-2357$ & 27 & + & 14 & 2607-2609 & 3 & FP & & & & \\
\hline
\end{tabular}

\footnotetext{
${ }^{a}(+)$ correct answer, (FP) false positive error, (FN) false negative error, (UZ) uncertain zone, (FE) error due to filtering.
} 
type error. However, one may argue that in some shaly sections of reservoir where it is also fractured, the shale volume or gamma ray will filter fractures too, which is in conflict with our objective. Therefore, only using such a filter, it is unlikely to achieve $100 \%$ recovery.

In Fig. 5, approximated section of water saturation and gamma ray $\log$ at level 5 as decomposed using mother wavelet bior- 4.4 as well as location of fractured zones and position of FP errors are shown. In this figure a threshold limit of $60 \%$ for gamma ray is defined which excludes any zone with gamma ray greater than $60 \%$ from being fractured. In this research the threshold limit found to be $25 \%$ and $60 \%$ for shale volume and gamma ray logs respectively. In Table 5 nonfractured zones, as determined after applying gamma ray filter, are identified. As fractured zones are already known to us (from image $\log$ ) zones which are correctly categorized as fractured zones are marked with a star sign. Both Table 5 and Fig. 5 indicate that the applied method has filtered part of the fractured zone in the upper section of the reservoir, as expected.

As is seen from Table 5, gamma ray filter (shale volume) resulted in improving fracture detection in 50\% of cases. More importantly, correct filter response corresponds to, in general, FP errors or uncertain zone of fractures extracted from water saturation log. This is clearly seen from Fig. 5 where FP and uncertain zones correspond to an increase in gamma ray log.

\subsection{False negative (FN) error}

This error occurs once a reduction in water saturation is observed which is interpreted as an absence of fractured zone, but instead, it should indicate otherwise i.e. a fractured zone exists (see Fig. 6). Here we investigate the sources for these conflicting conclusions by filtering FN error.

The source of FN error should be sought within the fracture properties including filling, continuity, density and opening (aperture). Other parameters such as the kind of host rock, reservoir pressure and mud pressure, water saturation within studied portion, production history and injection are some of the parameters that could be a source for FN error and needs to be studied in this context. In this study and based on the available data it was proven that the host rock does not have significant influence on fractures in terms of increasing water saturation and therefore will not be an appropriate filter to be used. Only in interpretation of image log obtained from one of the wells, fractures were classified into continuous and discontinuous groups where all FN errors coincide with discontinuous fractures. Due to a limited number of cases observed as such, generalizing this property as being a filter for FN errors could not be justified.

As there was no information about the properties mentioned above in the studied wells it was not practical to identify a filter for FN errors and generalize it.

\subsection{Uncertain zones}

This zone corresponds to a part of the reservoir where the variability in water saturation is low and discrimination of fractured zones is practically impossible. From the trend of water saturation changes in studied wells following statements may be drawn in terms of factors important in forming the uncertain zone:

a) within water bearing zones of reservoir water saturation is not altered with the presence of shale or fractured zone and generally water saturation is high,

b) zones with no fracture and low variability in shale volume may lead to the presence of uncertain zones; and

c) a zone across which an increase in water saturation, corresponding to a fractured zone, is neutralised due to a reduction in shale volume could be considered as an uncertain zone.
To filter the uncertain zone, based on the above statements, following treatments may be employed:

a) if the water saturation across the bottom section of reservoir is close to $100 \%$ this could be used as an indication of water bearing zone and as a result the presence of shale or fractured zone could not cause an increase in water saturation. This leads to the conclusion that at this section detecting the fractured zone using water saturation log is impossible and thus this is an uncertain zone,

b) within the intervals during which no significant variation in shale volume is observed, the water saturation log could show two different behaviours. If water saturation log increases, which is indicative of a potential fractured zone, this zone is not considered as an uncertain zone anymore. However, if the water saturation $\log$ does not show any variations this concludes that there was no fractured zone causing the water saturation to increase, which ultimately means that this is not an uncertain zone; and

c) in a zone across which variation in shale volume is observed but water saturation does not change, most probably reduction in shale volume corresponds to the presence of a fractured zone. Therefore, if in a part of reservoir water saturation is constant but shale volume varies, a reduction in shale volume could mean the existence of a fractured zone. This is to say that this zone is not an uncertain zone.

Table 6 summarizes the process of filtering an uncertain zone.

In Fig. 7 the uncertain zone corresponding to well no. 2 is shown. It can be seen that this zone is in the water bearing section of reservoir and GR variation as well as presence of a fractured zone do not have a significant effect on water saturation in a way that water saturation remains $100 \%$. Therefore, in this zone detection of a fractured zone is impossible and this zone is in fact an uncertain zone.

\section{Fractured zone detection after filtering errors}

It was seen here that in the absence of sufficient information, filtering FN error types could not be carried out. So, only sources for FP errors as well as uncertain zones considered to filter the errors through the process of fracture detection. As it was demonstrated, through the filtering process the accuracy in fractured zone detection was increased. For example, in Table 7 the final results of fracture detection after filtering is shown for well 2. It is important to note that in this well, as the uncertain zone is located within the water bearing section of reservoir, filtering this zone was practically impossible and hence in this well only FP error type was reduced. In Table 8, final results of fractured zone detection in well 2 are given. Comparing the results of this table with those of Table 4, it is concluded that the accuracy of fracture detection after filtering has increased by $5 \%$ and the recovery percentage has risen up to $69 \%$ (from $64 \%$ as was the case before filtering).

\section{Correlation between signal energy in fractured zone and fracture frequency}

As described above, applying wavelet transform on water saturation $\log$ and subsequent filtering of some errors through GR log, it was possible to identify the fractured zones. The accuracy of the method

Table 8

Fracture detection recovery after applying filters.

\begin{tabular}{lcc}
\hline Error types & Depth interval & Recovery \\
\cline { 2 - 2 } & $(\mathrm{m})$ & $(\%)$ \\
\hline No error & 315 & 69 \\
FP & 8 & 2 \\
FN & 42 & 9 \\
Uncertain & 67 & 15 \\
Error due to filtering & 23 & 5 \\
\hline
\end{tabular}


Table 9

Fracture frequency (density) and signal energy corresponding to each fractured zone in well 2.

\begin{tabular}{|c|c|c|c|c|c|c|c|c|c|c|c|}
\hline \multirow[t]{2}{*}{ Row } & \multirow{2}{*}{$\frac{\text { Fracture zone }}{(\mathrm{m})}$} & \multirow{2}{*}{$\begin{array}{l}\text { Signal } \\
\text { energy }\end{array}$} & \multirow{2}{*}{$\frac{\text { Fracture density }}{\text { (fracture } / \mathrm{m})}$} & \multicolumn{2}{|l|}{ No. of fractures } & \multirow[t]{2}{*}{ Row } & \multirow{2}{*}{$\frac{\text { Fracture zone }}{(\mathrm{m})}$} & \multirow{2}{*}{$\begin{array}{l}\text { Signal } \\
\text { energy }\end{array}$} & \multirow{2}{*}{$\frac{\text { Fracture density }}{\text { (fracture } / \mathrm{m} \text { ) }}$} & \multicolumn{2}{|l|}{ No. of fractures } \\
\hline & & & & Cont. open frac. & Discon. open frac. & & & & & Cont. open frac. & Discon. open frac \\
\hline 1 & $2282-2286$ & 3.0 & 4.60 & 6 & 17 & 8 & $2440-2444$ & 1.3 & 2.00 & 3 & 7 \\
\hline 2 & $2296-2322$ & 19.8 & 3.55 & 21 & 75 & 9 & $2453-2459$ & 2.1 & 2.43 & 12 & 5 \\
\hline 3 & $2331-2357$ & 21.5 & 0.85 & 5 & 18 & 10 & $2469-2491$ & 14.2 & 0.70 & 7 & 25 \\
\hline 4 & $2363-2370$ & 6.3 & 1.87 & 4 & 11 & 11 & $2576-2586$ & 8.4 & 1.82 & 11 & 9 \\
\hline 5 & $2381-2389$ & 2.4 & 1.78 & 3 & 13 & 12 & $2626-2628$ & 2.5 & 2.33 & 1 & 6 \\
\hline 6 & $2398-2401$ & 1.4 & 3.25 & 8 & 5 & 13 & $2637-2640$ & 3.4 & 5.50 & 8 & 14 \\
\hline 7 & $2417-2434$ & 12.7 & 2.78 & 27 & 23 & & & & & & \\
\hline
\end{tabular}

proved to be around $70 \%$. The remaining unanswered question is that how many single fractures exist in each fractured zone (fracture frequency or density)? The answer is sought in a correlation analysis between signal energy and fracture frequency (density).

In Table 9, fractured zones interval, number of fractures and the signal energy in each fractured zones, as detected through this study, are given. In this table zones corresponding to both FP and FN errors as well as uncertain intervals were excluded and the results are limited to the intervals corresponding to $70 \%$ accuracy.

In Fig. 8 the approximated section of water saturation log in well 2 as analysed using mother wavelet bior-4.4 at level 5 was plotted versus the number of fractures within the fractured zone. As seen from this figure, in general, energy level increases as the number of fractures is increased. Excluding depth interval 2331-2357 m, a linear relationship exists between number of fractures $\left(f_{n}\right)$ and signal energy $\left(E_{s}\right)$. A linear relation is desired which enables us to generalize the results to other cases more favourably. The linear relation after discarding the out of range data and applying the minimum sum of square error method is obtained as follows (see Fig. 8)

$E_{\mathrm{s}}=0.2173 f_{n}+0.6447$

having a correlation coefficient of 0.78 ; which is considered to be a reasonable value, statistically. Similar results were obtained in other wells, which leads to a conclusion that using the approach proposed in this paper, it is possible to detect the fractured zones and the number of fractures in each zone with a reasonably high accuracy.

\section{Conclusion}

Despite critical importance of fracture detection in modeling of fractured reservoirs, limited research has been carried out using well logs. This is perhaps due to lack of any significant responses of well logs to fractures. This difficulty was tackled in this paper with the fundamental assumption that high fracture density in a fractured zone could influence the well log responses. Therefore, it was concluded that studying the low frequency variation of well logs through the use of wavelet and wavelet packet techniques, detection of fractured zones should be potentially

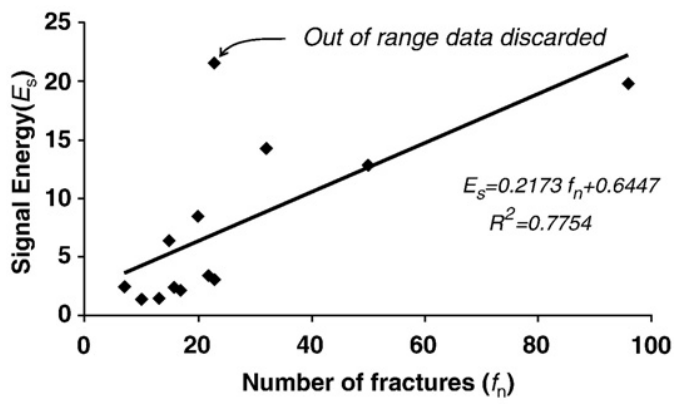

Fig. 8. Correlation between number of fractures $\left(f_{n}\right)$ and signal energy $\left(E_{s}\right)$ in approximated section of $S_{\mathrm{w}} \log$ in well 2 analysed using mother wavelet bior-4.4 at level 5. possible. As water saturation is expected to increase in water wet fractured zones, the water saturation log was used to identify the fractured zones where the image logs were used simultaneously to calibrate the results. The water saturation log was decomposed using wavelet packet and Fourier transforms after which the fractured zones were shown to indicate a good correlation (accuracy of about 64\%) with approximated section of wavelet transform of water saturation log and where this log shows increased values. The accuracy of the method was increased by carrying out filtering of the errors corresponding to three different error categories: false positive (FP), false negative (FN) and uncertain zones. The errors in uncertain zone were reduced through shale volume or GR logs as well as fracture and other reservoir properties. In this study the reduction of FN error was not practically possible, as the uncertain zone in some wells was within the water bearing section of the reservoir. After filtering, the accuracy of the method increased by $5 \%$ and became $69 \%$. Finally, a positive linear correlation was derived between energy signal of approximated section of water saturation log and the number of fractures in each fractured zone. The proposed method successfully detected the fractures in four studied wells of one of the oilfields in southwest Iran. This indicates that the approach used in this paper, is promising and can be extended to act as a robust methodology in fracture detection by further examination in new fields.

\section{Acknowledgement}

The authors would like to express their sincere thanks to the National Iranian South Oil Company (NISOC) and Mr Taghavipour and $\mathrm{Mr}$ Kordavani in NISOC for their assistance in providing the information and their technical input to this work.

\section{References}

Behrens, R.A., Macleod, M.K., Tran, T.T., Alimi, A.O., 1998. Incorporating seismic attribute maps in 3D reservoir models. SPE Reserv. Evalu. 1, 122-126.

Daubechies, I., 1988. Orthogonal bases of compactly supported wavelets. Commun. Pure Appl. Math. XLI, 909-996.

Daiguji, M., Kudo, O., Wada, T., 1997. Application of wavelet analysis to fault detection in oil refinery. Computers Chem. Engng. 21, S1117-S1122.

Dutta, P., Singh, S.K., Al-Genai, J., Akhtar, A., Akbar, M., 2007. A novel approach to fracture characterization utilizing borehole seismic data. 15th SPE Middle East Oil \& Gas Show and Conference, Bahrain. Paper SPE 105427 (6 pp).

Fathi, N., Delshad, M., Sepehrnoori, K., Nguyen, Q.P., Zhang, J., 2008. Chemical flooding of fractured carbonates using wettability modifiers. 2008 SPE/DOE Improved Oil Recovery Symposium held in Tulsa, Oklahoma, U.S.A., 19 Pages, Paper SPE 113369.

Flavio, S.A., Gregor, P.E., 1999. The velocity-deviation $\log$ A tool to predict pore type and permeability trends in carbonate drill holes from sonic and porosity or density logs. Am. Assoc. Pet. Geol. Bull. 83 (3), 450-466.

Hsu, K., Brie, A., Plumb, R.A., 1987. A new method for fracture identification using array sonic TOOIS. J. Pet. Technol. 677-683 June 1987, Paper SPE 14397.

Mallat, S., 1989. A theory for multiresolution signal decomposition: the wavelet representation. IEEE Trans. Pattern Anal. Mach. Intell. 11, 674-693.

Martinez-Torres, L.P., 2002. Characterization of Naturally Fractured Reservoirs from Conventional Well Logs. M.Sc. Thesis, University of Oklahoma. USA.

Mohebbi, A.R., Haghighi, M., Sahimi, M., 2007. Using conventional logs for fracture detection and characterization in one of Iranian field. International Petroleum Technology Conference held in Dubai, U.A.E., 4-6 December 2007, Paper IPTC 11186.

Nelson, R.A., 2001. Geologic Analysis of Naturally Fractured Reservoirs, SECOND EDITION. Gulf Professional Publishing, U.S.A. 332 Pages.

Ozkaya, S.I., Siyabi, S., 2008. Detection of fracture corridors from dynamic data by factor analysis. SPE Saudi Arabia Section Technical Symposium held in Alkhobar, Paper SPE 120812. 
Roehl, P.O., Choduette, P.W., 1985. Carbonate Petroleum Reservoirs. Spring-Verlag New York. (622 pages).

Sahimi, M., Hashemi, M., 2001. Wavelet identification of the spatial distribution of fractures. Geophys. Reserv. Lett. 28 (4), 611-614.

Schlumberger Log Interpretation Principles/Applications. 1998. Seven Printing. March Sugar Land, Texas 77478

Serra, O., 1989. Formation MicroScanner Image Interpretation, Schlumberger Education Services.

Sidney Burrus, C., Guo, H., Gopinath, R.A., 1997. Introduction to Wavelet and Wavelet Transforms: a Primer. Prentice Hall, NJ. (268 pages).
Song, X., Zhu, Y., Iiu, Q., Chen, J., Ren, D., Li, Y., Wang, B., Liao, M., 1998. Identification and distribution of natural fractures. SPE International Conference and Exhibition in China held In Beijing, Paper SPE 50877

Surjaatmadja, J.B., Stephenson, S., Cheng, A., 2002. Analysis of generated and reflected pressure waves during fracturing reveals fracture behavior. SPE Annual Technical Conference and Exhibition held in San Antonio, Texas, Paper SPE 77598.

Thompson, L.B., 2000. Fractured reservoirs: integration is the key of optimization. Distinguished Author Series, 52-54, SPE 56010.

Tran, N.H., 2004. Characterization and Modeling of Naturally Fractured Reservoirs. Ph.D. Thesis, University of New South Wales, Australia. 